\title{
CISTO SIMPLES DE TESTÍCULO - RELATO DE CASO E REVISÃO DA LITERATURA
}

\author{
Davi E. Lamego Rezende ${ }^{1}$
}

Resumo 0 autor relata um achado de cisto simples no testículo de um paciente adulto durante estudo ultra-sonográfico. Faz uma revisão da literatura, sugere acompanhamento e conduta conservadora.

Unitermos: Testículo. Cisto. Cisto de testículo.

Abstract Simple testicular cyst - case report and review of the literature.

The author reports a case of an adult patient with a simple testicular cyst diagnosed by ultrasound. A review of the literature is presented and a conservative treatment approach and follow-up is recommended.

Key words: Testis. Cyst. Testicular cyst.

\section{RELATO DO CASO}

Paciente de 46 anos de idade, branco, relatando dor e desconforto no testículo direito. Negava história de trauma ou processos inflamatórios.

Ao exame físico observava-se bolsa escrotal simétrica, testículos com conformação e dimensões normais. Sinais de hidrocele à direita. O testítulo esquerdo apresentava-se normal à palpação.

O estudo ultra-sonográfico foi realizado com sonda linear de alta resolução, na freqüência de $10 \mathrm{MHz}$. O exame demonstrou testículos tópicos, com forma normal e contornos regulares, pequena hidrocele $\left(3 \mathrm{~cm}^{3}\right)$ à direita, ausência de sinais de varicocele, epidídimos simétricos e anatômicos. No terço médio do testículo esquerdo foi observada área cística, de paredes finas, conteúdo homogêneo, medindo 6,1 × 4,3 mm (Figuras 1 e 2). A análise dopplervelocimétrica foi normal nos testículos, exceto na área cística, onde foram identificados sinais de fluxo.

Devido aos achados ultra-sonográficos sugestivos de benignidade e à nãopalpação do cisto, orientamos o paciente para realização de controle ultra-sonográfico trimestral.

O estudo ultra-sonográfico do abdome, realizado posteriormente, não demonstrou anormalidades.

1. Professor Assistente do Departamento de Radiodiagnóstico da Faculdade de Ciências Médicas de Minas Gerais, Belo Horizonte, MG.

Endereço para correspondência: Prof. Dr. Davi E. Lamego Rezende. Av. Bernardo Monteiro, 1311. Belo Horizonte, MG 30150-281. E-mail: patde@ig.com.br

Aceito para publicação em 25/4/2001

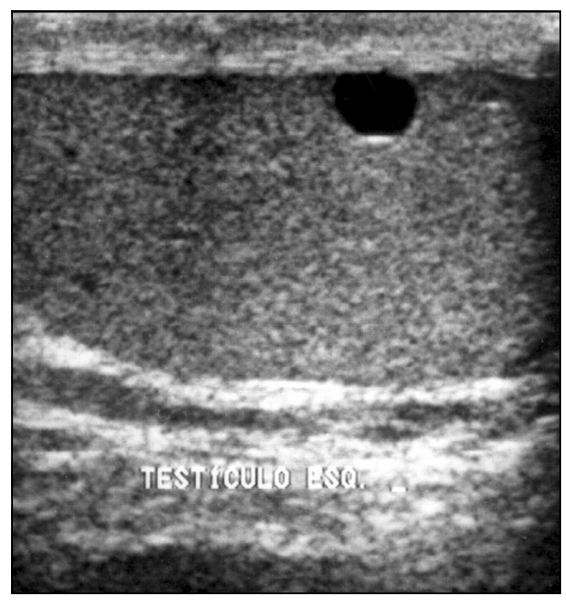

Figura 1. Imagem longitudinal do testículo esquerdo mostrando cisto no terço médio, superfície anterior, com paredes finas e irregulares.

\section{DISCUSSÃO}

$\mathrm{O}$ achado de cisto simples de testículo é bastante raro. Desde o primeiro caso descrito por Schmidt ${ }^{(\mathbf{1})}$, em 1966, poucos outros casos foram publicados. Pode ocorrer em qualquer faixa etária, desde neonatos $^{(2)}$ até idosos ${ }^{(3,4)}$.

A origem destes cistos permanece imprecisa e diversos autores têm considerado três fatores causais: a) anomalia congênita; b) trauma; c) infecção. Possivelmente, há superposição de dois ou mais fatores ${ }^{(\mathbf{3 , 5}, \mathbf{6})}$.

Sonograficamente, um cisto simples do testículo é uma imagem anecóica, localizada dentro do parênquima testicu-

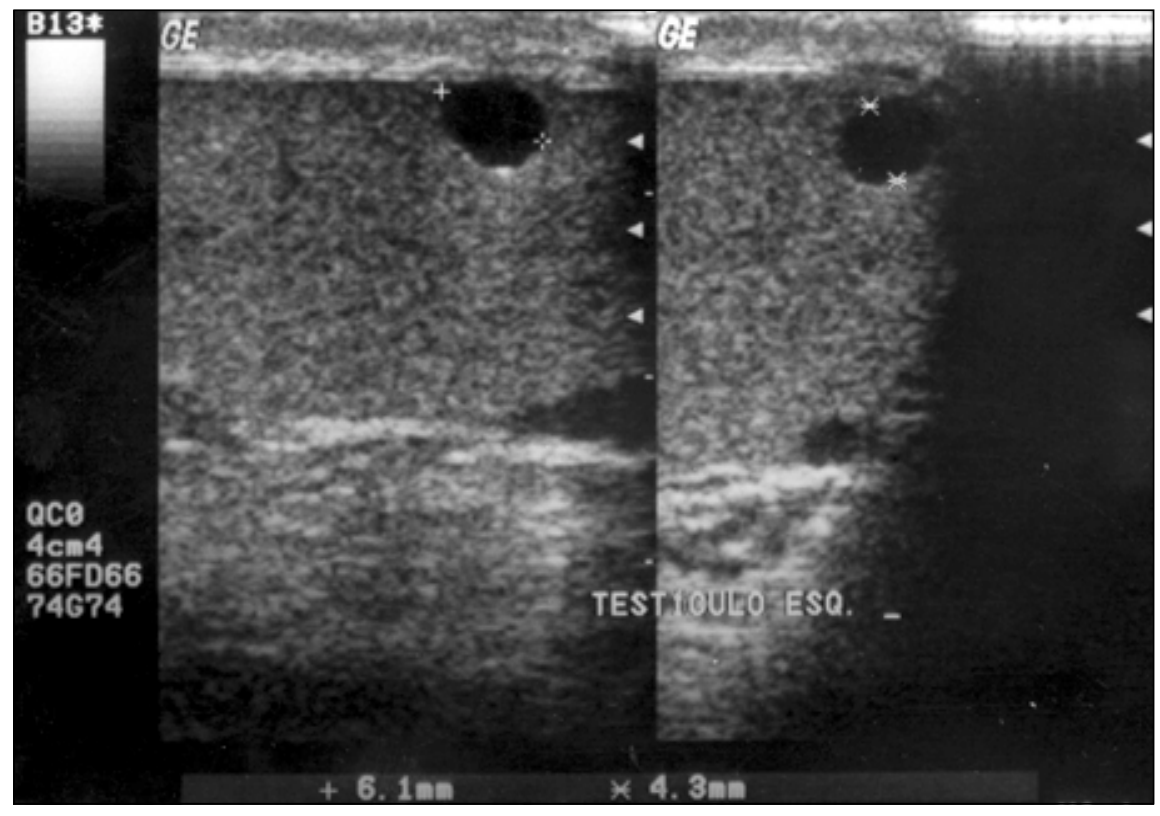

Figura 2. Imagens transversais do testículo e dimensões do cisto. 
lar. Tem contornos bem definidos e reforço acústico posterior. Ao estudo dopplervelocimétrico não há sinal de fluxo.

Com base nessas características, devemos excluir: a) cisto epidermóide; b) neoplasias; c) cistos da túnica albugínea; d) espermatocele; e) lesões extratesticulares; f) teratoma ${ }^{(7-9)}$.

Nos casos de cistos de testículo nãoneoplásicos, dois tipos devem ser diferenciados: cistos da túnica albugínea e cistos intratesticulares. A distinção entre estes dois tipos é feita, principalmente, à palpação. Ao contrário dos cistos da túnica albugínea, os cistos intratesticulares são descobertos apenas pela ultra-sonografia, não sendo palpáveis ${ }^{\left({ }^{(6)}\right.}$.

Estes cistos são geralmente solitários, embora possam ocorrer bilateralmente ${ }^{(6)}$.
Cistos benignos também podem ocorrer em pacientes portadores de síndromes como von Hippel-Lindau ${ }^{(\mathbf{1 0})}$ e displasias císticas $^{(11)}$.

Neste caso descrito, a área cística não era acompanhada de outras alterações testiculares ou abdominais.

Dispondo dos recursos da ultra-sonografia de alta resolução, sugerimos seguimento trimestral e tratamento conservador, evitando enucleação ou orquiectomia $^{(\mathbf{1 2})}$.

\section{REFERÊNCIAS}

1. Schmidt SS. Congenital simple cyst of the testis: a hitherto undescribed lesion. J Urol 1966;96: 236-8.

2. Slaughenhoupt B, Klauber G. Simple testicular cyst in the neonate. J Pediatr Surg 1995;30:6367.

3. Takihara H, Valvo J, Tokuhara M, Cockett AT.
Intratesticular cysts. Urology 1982;20:80-2.

4. Gooding GAW, Leonhardt W, Stein R. Testicular cysts: US findings. Radiology 1987;163:537-8.

5. Haber MM, Cohen MB. Simple cysts of testis. Urology 1992;39:563-5.

6. Hamm B, Fobbe F, Loy V. Testicular cysts: differentiation with US and clinical findings. Radiology 1988;168:19-23.

7. Langer JE, Ramchandani P, Siegelman SE, Banner MP. Epidermoid cysts of the testicle: sonographic and MR imaging features. AJR 1999;173: 1295-9.

8. Dmochowski RR, Rudy DC, Weitzner S, Corriere JN Jr. Simple cyst of the testis. J Urol 1989; 142:1078-81.

9. Davis RS. Intratesticular spermatocele. Urology 1998;51(5A Suppl.):167-9.

10. Brown JA, Segura JW. A symptomatic testicular cyst in a patient with von Hippel-Lindau disease. Urology 1996;48:494-5.

11. Zaragoza MR, Buckler LB, Parikh MJ. Cystic dysplasia of the testis: an unusual cause of a pediatric scrotal mass. Urology 1996;47:244-7.

12. Lam KY. Bilateral intratesticular cyst - a specific entity. Scand J Urol Nephrol 1996;30:329-31. 